Grain refinement of DC cast magnesium alloys with intensive melt shearing

This content has been downloaded from IOPscience. Please scroll down to see the full text. 2012 IOP Conf. Ser.: Mater. Sci. Eng. 27012043

(http://iopscience.iop.org/1757-899X/27/1/012043)

View the table of contents for this issue, or go to the journal homepage for more

Download details:

IP Address: 134.83.1.242

This content was downloaded on 11/05/2015 at 10:37

Please note that terms and conditions apply. 


\title{
Grain refinement of DC cast magnesium alloys with intensive melt shearing
}

\author{
Y B Zuo, B Jiang, Y Zhang, Z Fan \\ The EPSRC Centre - LiME, BCAST, Brunel University, Uxbridge, UB8 3PH, UK \\ E-mail: yubo.zuo@brunel.ac.uk,bo.jiang@brunel.ac.uk, zhongyun.fan@brunel.ac.uk
}

\begin{abstract}
A new direct chill (DC) casting process, melt conditioned DC (MC-DC) process, has been developed for the production of high quality billets/slabs of light alloys by application of intensive melt shearing through a rotor-stator high shear device during the DC casting process. The rotor-stator high shear device provides intensive melt shearing to disperse the naturally occurring oxide films, and other inclusions, while creating a microscopic flow pattern to homogenize the temperature and composition fields in the sump. In this paper, we report the grain refining effect of intensive melt shearing in the MC-DC casting processing. Experimental results on DC casting of Mg-alloys with and without intensive melt shearing have demonstrated that the MC-DC casting process can produce magnesium alloy billets with significantly refined microstructure. Such grain refinement in the MC-DC casting process can be attributed to enhanced heterogeneous nucleation by dispersed naturally occurring oxide particles, increased nuclei survival rate in uniform temperature and compositional fields in the sump, and potential contribution from dendrite arm fragmentation.
\end{abstract}

\section{Introduction}

Magnesium alloys have low density, high specific strength, high damping capacity, good castability and excellent electromagnetic shielding properties, which make them suitable for applications in many industrial sectors including automotive, aerospace, defence, electronics, healthcare, and sports equipment $[1,2]$. DC casting is a key technology for providing billets or slabs of magnesium alloys. However, the billets or slabs made by the conventional DC casting process often have coarse and nonuniform microstructures, severe chemical segregation, porosity, and hot tearing, which not only burden downstream thermo-mechanical processing, but also have a negative influence on the mechanical properties of the final products. Grain refinement by inoculation with chemical grain refiners is an important and effective approach for mitigating such problems [3, 4]. Although grain refinement of magnesium alloys has attracted intensive research [2, 5-7] the search for new and effective grain refiners, and methods for grain refinement still continues. Contemporary research on grain refinement of magnesium alloys has mainly focused on searching and developing new chemical grain refiners and on the application of external physical fields including electromagnetic and ultrasonic fields, for example [8]. Recently, Fan and his co-workers [9-12] have found that the intensive melt shearing provided by a twin-screw mechanism has a significant grain refining effect on both aluminium and magnesium alloys. Based on a similar principle, a rotor-stator high shear device for intensive melt shearing has been developed [13]. In the present work, melt conditioned DC (MCDC) casting by combining the conventional DC casting with the rotor-stator high shear device was used for the production of high quality magnesium alloy billets. This paper presents our experimental 
results on microstructures of $\mathrm{Mg}$-alloys produced by the newly developed $\mathrm{MC}$-DC casting technology with intensive melt shearing. The discussion will be focused on the mechanisms of grain refinement.

\section{Experimental procedure}

Commercial magnesium alloys AZ91D (Mg-8.67Al-0.62Zn-0.21Mn, all compositions are in wt \%), and AZ31 (Mg-2.92Al-0.85Zn-0.36Mn) were used in the present work. The measured liquidus is $600^{\circ} \mathrm{C}$ for AZ91D and $630^{\circ} \mathrm{C}$ for AZ31. The alloys were melted at $680^{\circ} \mathrm{C}$ in a steel crucible under a protective atmosphere containing a mixture of $\mathrm{N}_{2}$ and $0.5 \mathrm{vol} \% \mathrm{SF}_{6}$. The alloy melts were then DC cast with and without intensive melt shearing. AZ91D and AZ31 alloys were cast at $650^{\circ} \mathrm{C}$ and $680^{\circ} \mathrm{C}$, respectively. Intensive melt shearing was achieved by submerging a high shear device in the sump of the DC caster, as shown in figure 1. The high shear device was operated at high speed (5000-15000RPM) to provide in situ intensive melt shearing in the sump. The shear rate inside the high shear device can be as high as $10^{5} / \mathrm{s}$ depending on the rotation speed of the rotor and the gap between the rotor and stator. Samples were sectioned, mechanically polished and then examined by optical microscopy (OM) according to the standard metallographic procedures. To further understand the effect of melt shearing during DC casting on the microstructure, the temperature field was measured by using thermocouples attached to the high shear device and a data logger during the DC casting process. In figure 1, T1-T4 schematically marks the positions of the

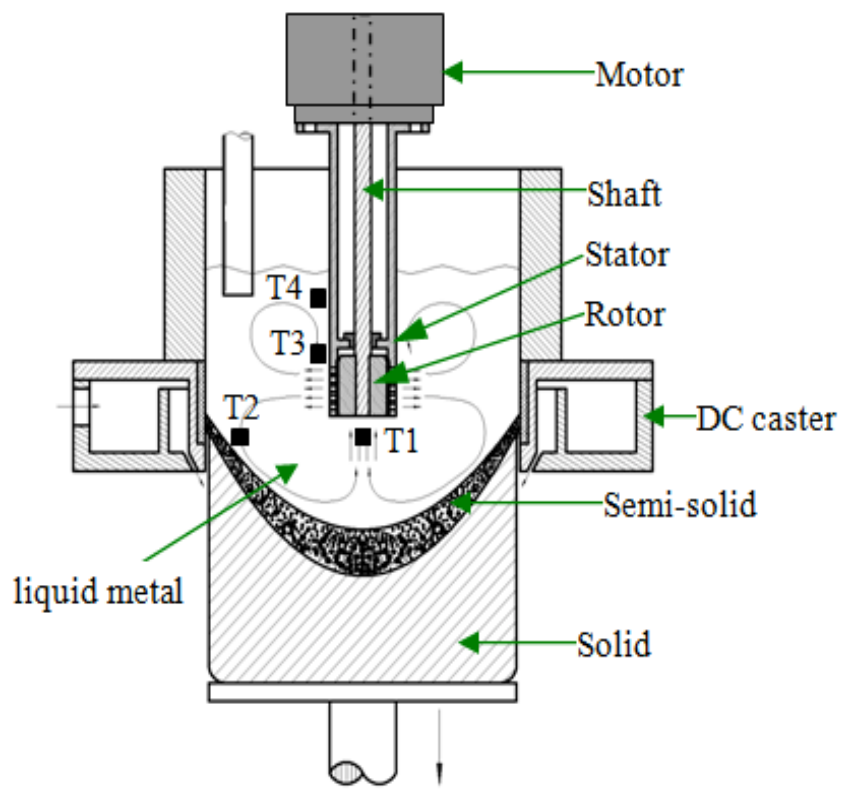

Figure 1. Schematic illustration of the DC casting process with the application of a rotor-stator high shearing unit. T1-T4 indicates the positions of thermocouples.

\section{Results}

In order to clearly demonstrate the effect of intensive melt shearing on microstructure, the high shear device was switched on during the DC casting process and the microstructure of the transitional zone was examined. figure 2 shows the microstructural transition of DC cast AZ91D magnesium alloy billet from the section without shearing to the section with shearing. The bottom half of the sample, without intensive melt shearing, shows coarse dendritic microstructure; but after switching on the high shear device, the microstructure is then transformed to a fine and uniform microstructure with spherical morphology.

The macrostructure was also examined to assess the structural uniformity of the DC cast billets. Figure 3 shows the macrographs of the sectioned DC cast AZ91D alloy billets with and without intensive melt shearing cast at $650^{\circ} \mathrm{C}$. The conventional DC cast sample (without shearing) has a coarse grain structure (figure 3a) but with intensive melt shearing the structure becomes much finer and more uniform (figure $3 \mathrm{~b}$ ). The microstructures of the same billets are shown in figure 4 . The conventional DC cast billet shows a coarse equiaxed dendritic microstructure with an average grain size around $550 \mu \mathrm{m}$ near to the billet surface (figure $4 \mathrm{a}$ ) and a coarse grain structure with an average grain size around $750 \mu \mathrm{m}$ at the centre (figure $4 \mathrm{~b}$ ). The microstructure of the billet with intensive melt 
The 3rd International Conference on Advances in Solidification Processes

IOP Publishing

IOP Conf. Series: Materials Science and Engineering 27 (2011) 012043

doi:10.1088/1757-899X/27/1/012043

shearing becomes much finer and more uniform. Both near the surface, figure $4 \mathrm{c}$, and at the centre of the billet, figure 4d, the microstructure is fine and uniform with an average grain size of $190 \mu \mathrm{m}$.

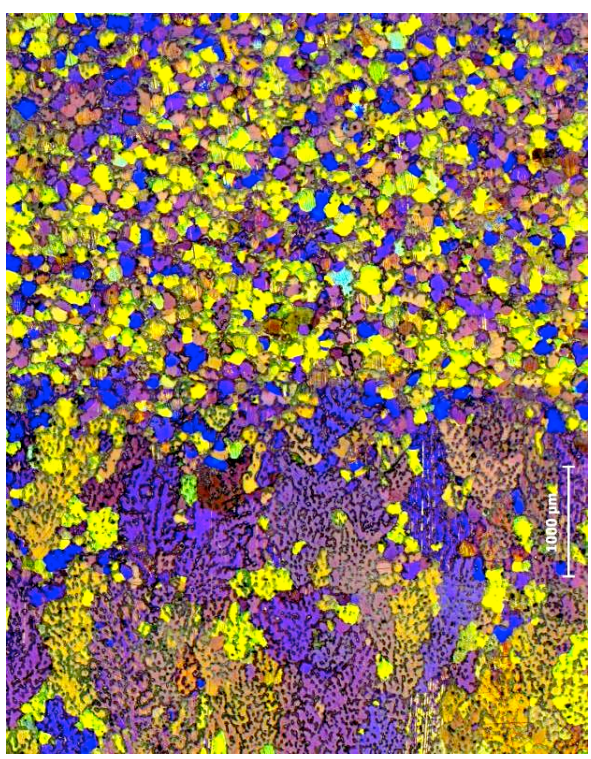

Figure 2. Variation of microstructure from the non-sheared zone (bottom) to the sheared zone (top) of an AZ91D alloy billet cast at $650^{\circ} \mathrm{C}$.
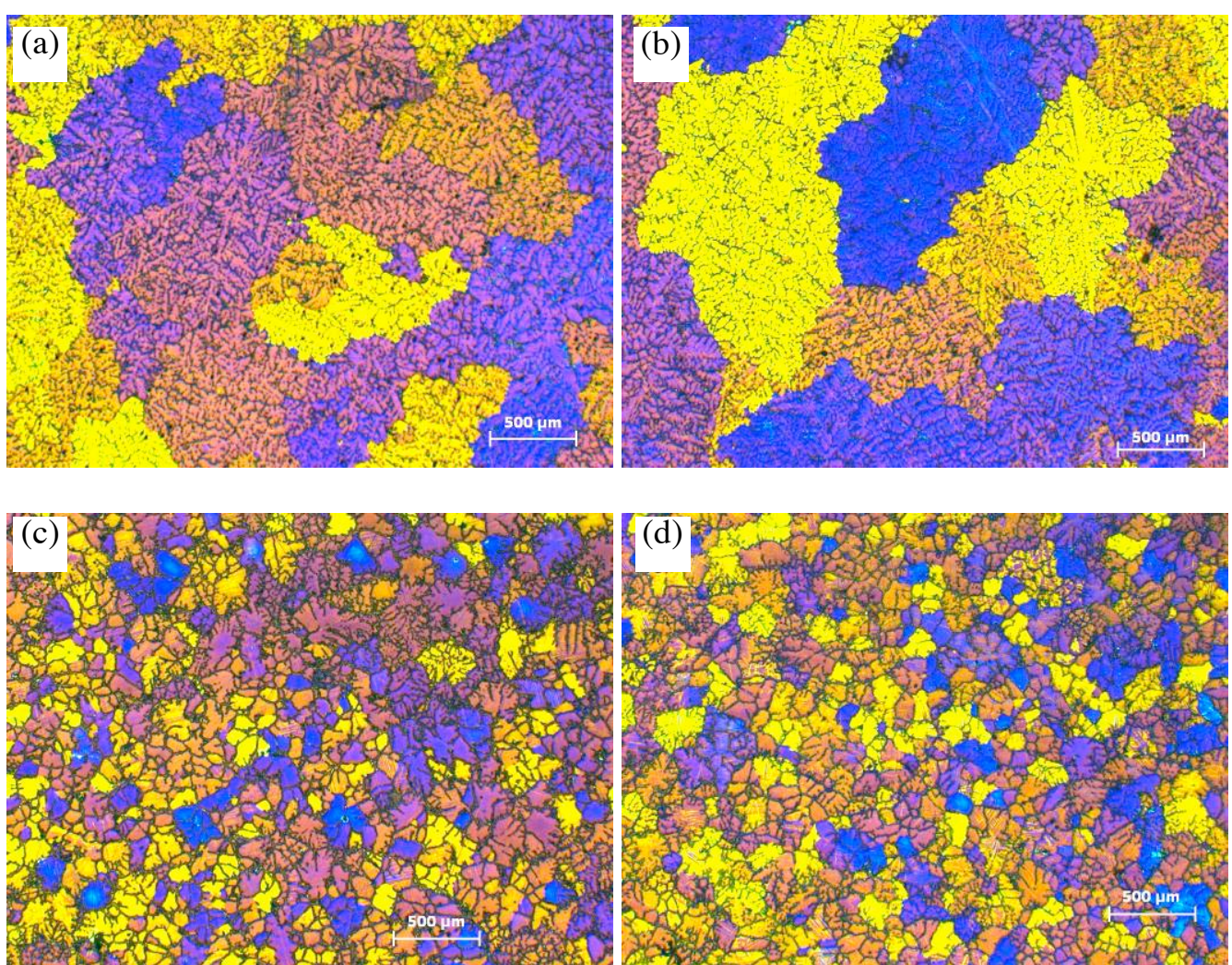

Figure 3. Macrographs of sectioned DC cast AZ91 alloy billets cast at $650^{\circ} \mathrm{C}$ without (a) and with (b) intensive melt shearing.
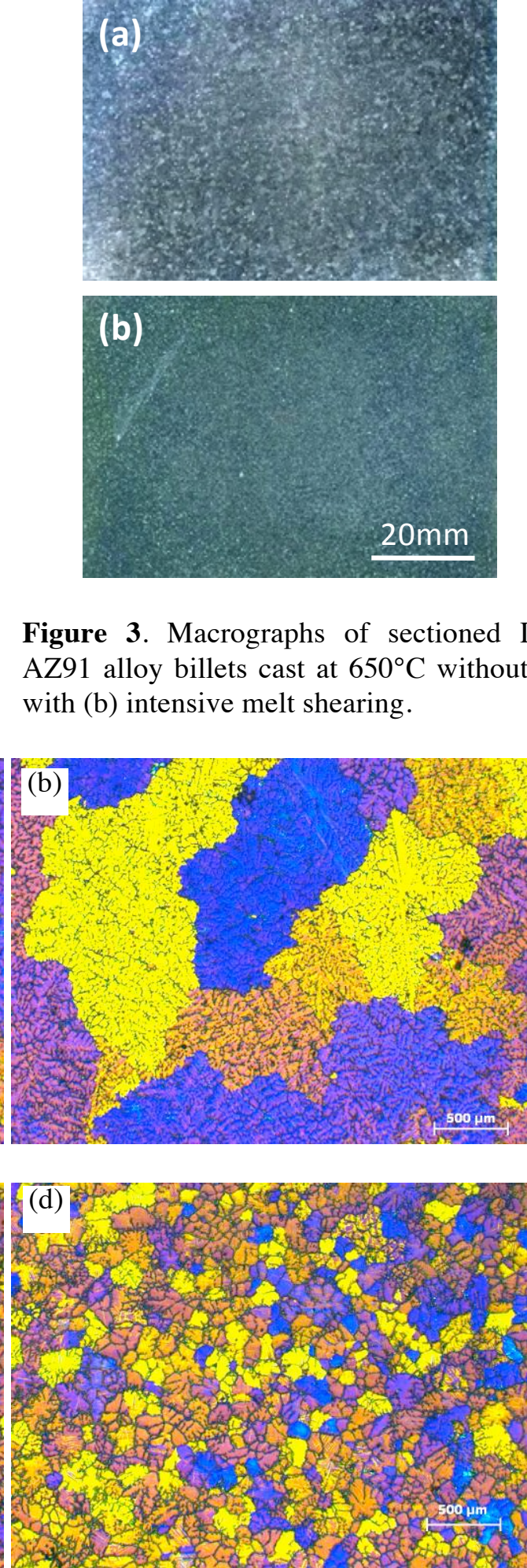

Figure 4. Microstructures of AZ91 alloy billets cast at $650^{\circ} \mathrm{C}$ with and without intensive melt shearing. (a) edge without shearing; (b) centre without shearing; (c) edge with shearing; (d) centre with shearing. 
The grain size distribution from the surface to the centre of the sheared and un-sheared billets is shown in figure 5. For the conventional DC cast billet, there is a thin layer with a finer microstructure, apart from that layer, the structure is dominiated by coarse grains. However, the billet cast with intensive melt shearing shows a uniform grain size distribution across the entire cross section. It is clear from the results above that during the DC casting process, the application of intensive melt shearing has a significant grain refining effect on the AZ91D magnesium alloy, and improves the uniformity of the microstructure.

To further confirm the grain refining effect of intensive melt shearing, the AZ31 magnesium alloy billets were cast at $680^{\circ} \mathrm{C}$ by the MC-DC casting process. Figure 6 shows the microstructures of the AZ31 Mg-alloy billets without (figure 6a) and with (figure 6b) intensive melt shearing. The microstructure of the conventionally DC cast AZ31 alloy billet shows a coarse dendritic structure with an average grain size of a few $\mathrm{mm}$; however, with the application of intensive melt shearing the microstructure becomes finer and equiaxed, with an average grain size of less than $200 \mu \mathrm{m}$.
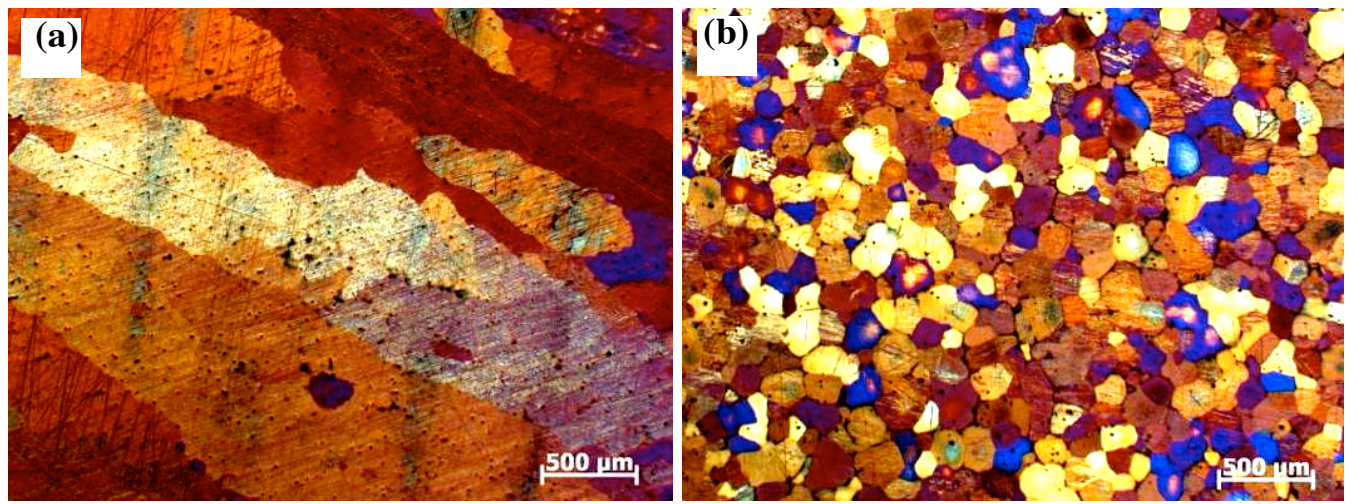

Figure 6. Microstructures of DC cast AZ31 Mg-alloy billets cast at $680^{\circ} \mathrm{C}$ (a) without and (b) with intensive melt shearing.

The temperature curves during DC casting of the AZ91D magnesium alloy are shown in figure 7, which were obtained through the thermocouples attached to the head of the high shear device. The positions of the thermocouples (T1-4) are schematically shown in figure 1. Based on the direct measurement of the sump depth with stainless steel rods, during casting process, the bottom of the high shear device was about $40 \mathrm{~mm}$ above the liquid/solid interface. With the start of the high shear device, there was a sharp change of the temperature field. The temperature curves became closer, which means the temperature field around the high shear unit was more uniform. After the application of the high shear, the temperature comes very close to the liquidus and then reaches a plateau, which is about $7^{\circ} \mathrm{C}$ lower than the liquidus. This could make an important contribution to the grain refinement of the microstructure.

\section{Discussion}

The experimental results show that intensive melt shearing has a significant grain refining effect on magnesium alloys. In this section we discuss the mechanism of grain refinement by intensive melt shearing. 


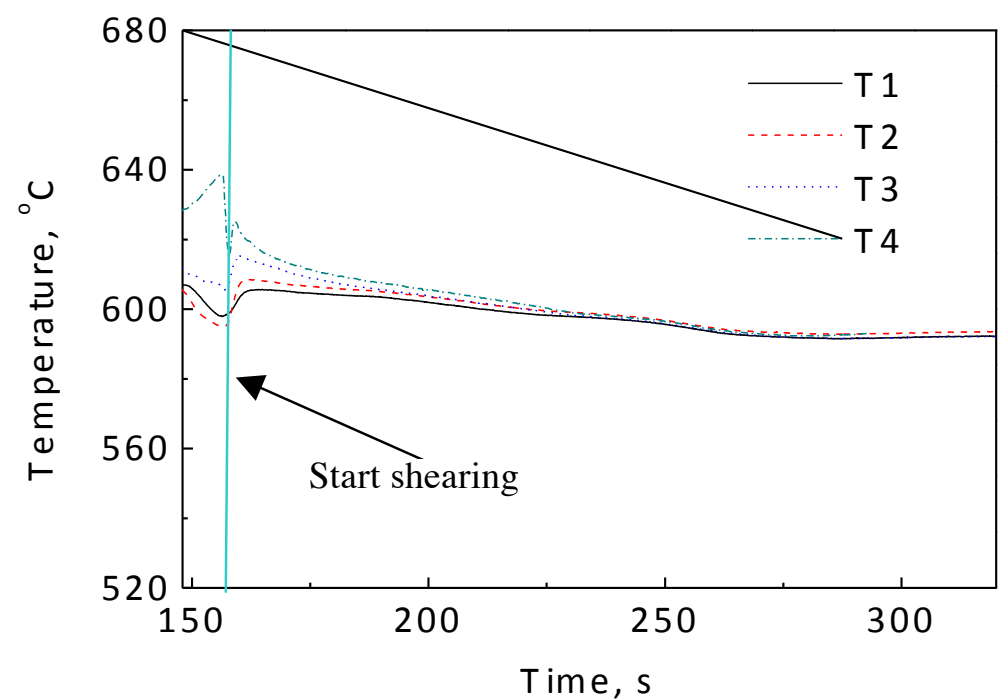

Figure 7. Measured temperature curves during MC-DC casting of AZ91D alloy. T1, centre, 10mm below the bottom of the high shear unit; T2, edge, $10 \mathrm{~mm}$ below the bottom of the high shear unit; T3, near to the centre, $30 \mathrm{~mm}$ above the bottom of the high shear unit; T4, near to the centre, $90 \mathrm{~mm}$ above the bottom of the high shear unit.

The high shear device is the key element in the MC-DC process to deliver the above mentioned advantages. The high shear device provides in situ conditioning of the liquid alloy during the DC casting process. The major function of the high shear device can be summarized as follows:

A high shear dispersive mixing action: The centrifugal force due to the rotation of the rotor generates a negative pressure inside the stator, which in turn sucks the melt below the high shear device into the stator and forces it to escape at high speed through the openings in the wall of the stator. This process subjects the melt to a high shear action in the gap between the rotor and the stator, and in the openings in the stator wall. The shear rate could be as high as $10^{5} / \mathrm{s}$, which is many orders of magnitude higher than the shear rate provided by the electromagnetic stirring. As a consequence of this intensive melt shearing the clusters of inclusions and oxide films naturally occurring in the melt will be dispersed into individual particles [9]. It is well documented that naturally occurring oxide films are hazardous to casting processes, and more importantly they deteriorate mechanical properties of the final cast products $[14,15]$. In the MC-DC process, the intensive melt shearing makes the usually harmful oxide films and other inclusions not only harmless, but also useful for grain refinement.

A macroscopic flow pattern: The rapid escaping liquid from the openings on the stator will create a macroscopic flow pattern in the sump, as schematically illustrated in figure 1 . This macroscopic flow provides a distributive mixing action in the sump, which homogenizes the temperature and chemical composition of the melt. As a consequence, the melt temperature and chemical composition in the sump will be uniform, at least around the tip of the high shear device (see figure 7). In addition, this macroscopic melt flow will be strong near the tip of the high shear device, and weak near the surface of the melt. This will prevent the occurrence of gas entrapment from the melt surface.

A reduced solute build-up at the solidification front: Due to the partitioning solute elements in the solid and liquid phases during solidification, there is usually a built-up of solute elements at the advancing solidification front. The forced convection generated by the high shear devise will suck the solute elements at the solidification front and distribute them uniformly in the sump. Such uniform 
fields of both temperature (slightly below liquidus) and chemical composition will create a condition, which promotes heterogeneous nucleation and equiaxed growth.

Enhanced heterogeneous nucleation in the MC-DC casting process is originated from the intensive melt shearing. Firstly, intensive melt shearing generates more potential nucleating particles by dispersing the oxide films. Previous study has confirmed that the potential number of nucleating particles can be increased by three orders of magnitude [16], and that $\mathrm{MgO}$ particles in a Mg-alloy melt do nucleate $\alpha-\mathrm{Mg}$ [9]. Increased nucleation events lead to grain refinement. Secondly, the uniform temperature field in the sump can increase the survival rate of the existing nuclei by avoiding their dissolution in the hotter melt (temperature greater than the liquidus). This also contributes to finer grains. Thirdly, there is a possibility that intensive melt shearing promotes fragmentation of dendrite arms since the melt temperature in the sump is below the liquidus (figure 7). This may also contribute partially to the grain refined microstructure in the MC-DC cast billets.

\section{Summary}

With the application of a rotor-stator high shear unit inside the DC casting mould, a new DC casting process, melt conditioned DC (MC-DC) process has been developed for production of high quality billets of magnesium alloys. In the MC-DC casting process, intensive melt shearing provided by the rotor-stator device is used to control the solidification process. Experimental results of DC casting of Mg-alloys with and without intensive melt shearing have demonstrated that the MC-DC casting process can produce light alloy billets with significantly refined microstructure. The intensive melt shearing can refine the grain size of AZ91D magnesium alloy from about $750 \mu \mathrm{m}$ to $190 \mu \mathrm{m}$. The mechanism of grain refinement is attributed to enhanced heterogeneous nucleation due to dispersed oxide particles, increased survival rate of existing nuclei due to the homogeneous temperature and composition fields in the sump and potential fragmentation of dendrite arms due to intensive melt shearing.

\section{References}

[1] Mordike B L and Ebert T 2001 Mater. Sci. Eng. A 302 37-45.

[2] Emley E F 1966 Principles of magnesium technology (Oxford:Pergamon Press).

[3] Eskin D G 2008 Physical metallurgy of direct chill casting of aluminum alloys (Boca Raton: CRC Press).

[4] Murty B S, Kori S A and Chakraborty M 2002 Inter. Mater. Rev. 47 3-29.

[5] David H S J, Ma Q, Easton M A, Cao P and Hildebrand Z 2005 Metall. Mater. Trans. A 36 $1669-1679$

[6] Zhang M X, Kelly P M, Qian M and Taylor J A 2005 Acta Mater. 53 3261-3270.

[7] Easton M A, Schiffl A, Yao J Y and Kaufmann H 2006 Scripta Mater. 55 379-382.

[8] Cui J Z , Zhang Z Q and Le Q C 2010 Trans. Nonferrous Met. Soc. China 20 s297-s305.

[9] Fan Z, Wang Y, Xia M and Arumuganathar S 2009 Acta Mater. 57 4891-4901.

[10] Zuo Y, Li H, Xia M, Jiang B and Scamans G M and Fan Z 2011 Scripta Mater. 64 209-212.

[11] Zuo Y B, Xia M, Liang S, Wang Y, Scamans G and Fan Z 2011 Mater. Sci. Technol. 27 101107.

[12] Fan Z and Liu G 2005 Acta Mater. 53 4345-4357.

[13] Fan Z, Zuo Y B and Jiang B 2010 Apparatus and method for liquid metals treatment, Application No.1015498.7, UK Patent, 2010.

[14] Mirak A R, Divandari M, Boutorabi S M A and Campbell J 2007 Int. J. Cast Met. Res. 20 215220.

[15] Campbell J 2006 Mater. Sci. Technol. 22 127-145.

[16] Men H, Jiang B and Fan Z 2010 Acta Mater. 58 6526-6534. 